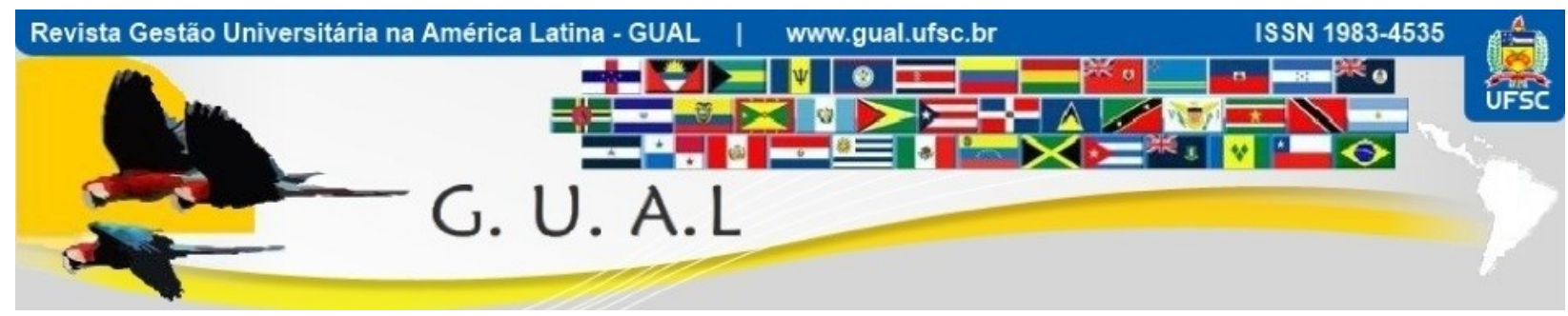

DOI: http://dx.doi.org/10.5007/1983-4535.2014v7n1p169

\title{
A INTELIGÊNCIA DISTRIBUÍDA COMO PLATAFORMA PARA O PLANEJAMENTO EM UNIVERSIDADE MULTICAMPI: ESTUDO DE CASO SOBRE INOVAÇÃO EM GESTÃO
}

\author{
DISTRIBUTED INTELLIGENCE AS A PLATFORM FOR PLANNING IN A \\ MULTICAMPI UNIVERSITY: A CASE STUDY ON INNOVATION MANAGEMENT
}

Mateus Panizzon, Doutorando Universidade de Caxias do Sul - UCS mpanizzo@ucs.br

Ana Cristina Fachinelli, Doutora Universidade de Caxias do Sul - UCS afachinelli@gmail.com

Eric Charles Henri Dorion, Doutor Universidade de Caxias do Sul - UCS edorion@ucs.br

Recebido em 31/março/2013

Aprovado em 17/setembro/2013

Sistema de Avaliação: Double Blind Review

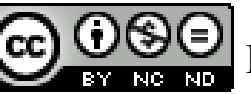
Esta obra está sob uma Licença Creative Commons Atribuição-Uso. 


\title{
RESUMO
}

A implantação de uma plataforma informatizada para a inteligência distribuída alinhada a uma metodologia institucional de planejamento possibilita uma mudança na organização, e pode, portanto, ser observada sob o ponto de vista da inovação em gestão. Este trabalho apresenta um estudo de caso descritivo sobre a inteligência distribuída como plataforma para o planejamento em uma instituição de ensino superior. Os resultados do estudo indicam que a implantação realizou transformações organizacionais, dinamizando o processo de planejamento institucional. Efetivamente, a adoção de tecnologia de informação sincronizada com uma metodologia de gestão estratégia ocasionou uma inovação em gestão no contexto pesquisado.

Palavras-chave: Instituições de ensino superior. Gestão estratégica. Tecnologia da informação. Inovação em gestão. Inteligência distribuída.

\begin{abstract}
The implementation of a computerized management platform aligned to a strategic institutional planning methodology enables a change in the organization, and therefore can be seen from the point of view of management innovation. This paper presents a descriptive case study in distributed intelligence as a platform for planning in an University. The results of the study indicate that deployment made organizational changes, streamlining the process of institutional planning. Indeed, the adoption of information technology with a synchronous methodology management strategy led to a management innovation in the studied context.
\end{abstract}

Key Words: Higher education institutions. Strategic management. Information technology. Management innovation. Distributed intelligence. 


\section{INTRODUÇÃO}

A relevância da gestão estratégica como ferramenta de coordenação das atividades da organização e do alinhamento das propostas do planejamento aumenta quando se trata de uma instituição complexa e dispersa geograficamente. Observa-se que em relação às empresas, as quais em virtude dos aspectos de competitividade necessitam aprimorar constantemente suas tecnologias de gestão, as instituições de ensino superior, em especial as de caráter comunitário, de modelo semelhante às instituições federais, vivenciam uma defasagem destas práticas. Isso ocorre em virtude da natureza acadêmica dessas instituições, cujos princípios diferem dos empresariais, na medida em que se veem obrigadas a adaptar mecanismos de planejamento, organização, direção e controle às suas estruturas organizacionais. De fato, na sua estrutura de processo decisório, predominam conselhos a lideranças e cargos temporários dos gestores. Por isso as políticas e objetivos normalmente são premeditados pela reitoria e pró-reitorias, e, tendo em vista a rotatividade da alta administração, ocasionada pela estrutura eleitoral, há impacto no foco e no de posicionamento a longo prazo da instituição (FORPLAD, 1995). Por muitas vezes, inclusive, as propostas dos gestores podem não corresponder às demandas e expectativas da comunidade acadêmica, o que vêm a gerar gargalos no que se refere à operacionalização das estratégias definidas. Neste sentido, uma sistemática de planejamento participativo, que contemple no diagnóstico e na definição do futuro pretendido o envolvimento de docentes, funcionários, alunos e representantes da comunidade externa, poderá ter maior adesão para sua operacionalização. Ao superar os interesses pessoais, estruturando diretrizes, objetivos e metas construídos e validados de forma conjunta, constrói-se uma base fundamental para a gestão estratégica, que é uma das abordagens necessárias para a profissionalização das IES, tanto públicas quanto privadas (MEYER Jr., 1998).

Além disso, uma sistemática de gestão estratégica não responde às demandas atuais de instituições de grande porte, quando está desassociada dos demais sistemas de informações. Além do componente humano, imprescindível na gestão estratégica, o uso das ferramentas tecnológicas disponíveis para a análise organizacional interna, como plataformas de Business Intelligence para mineração dos dados da organização, e para o monitoramento ambiental externo, como robôs de busca para inteligência via web, tornam-se diferenciais. Evidencia-se tal questão na medida em que essas informações capturadas podem ser tratadas e 
transformadas em inteligência, auxiliando na tomada de decisão e definição do posicionamento e objetivos a serem atingidos.

Entretanto, ainda que se perceba uma lacuna em termos de tecnologia de informação para o suporte da gestão estratégica, nos últimos anos têm surgido sistemas especializados para este fim e que contribuem para que a organização administre as informações pertinentes aos seus objetivos, metas e estratégias. No caso das IES, o papel destes sistemas, é, acima de tudo, proporcionar transparência nas informações de uma forma estruturada, possibilitando que a comunidade acadêmica se visualize e se envolva no processo, criando condições maiores para a operacionalização das definições e estratégias institucionais. Pesquisas acerca do alinhamento entre Estratégia e TI já foram realizadas em diversos contextos (BAKOS E TREACY, 1986; VENKATRAMAN, 1991; BRODBECK et al., 2003; REZENDE, 2003; MORAES, TERENCE e FILHO, 2004). Contudo, a aplicação destas tecnologias em IES é um assunto emergente (VICENZI, 2009). Neste sentido, a adoção de uma sistemática de gestão estratégica apoiada por sistemas de informação especialistas numa instituição de ensino superior pode ser analisada sob a ótica da inovação de gestão. Assim, o objetivo do presente artigo é analisar como uma instituição de ensino superior articula tecnologias da informação com seu sistema de planejamento, numa lógica de inovação em gestão.

Assim, o estudo de caso refere-se à utilização de uma plataforma informatizada de gestão estratégica (PGE) no Sistema de Planejamento Institucional (SPI) de uma instituição de ensino superior (IES). O objetivo é avaliar as mudanças ocorridas a partir da implantação de tecnologias de informação e de comunicação, sob o ponto de vista de uma inovação de gestão. A metodologia de pesquisa baseia-se em três partes: a) revisão bibliográfica trazendo os aspectos teóricos sobre inovação em gestão, inteligência distribuída e gestão estratégica em instituições de ensino superior; b) estudo de caso do PGE utilizado na IES; c) descrição das mudanças ocorridas na organização após a implantação do Sistema de Planejamento Institucional (SPI) em conjunto com a Plataforma de Gestão Estratégica (SGE), sob a ótica da inovação em gestão no contexto da universidade. A figura-conceito 1 representa a avaliação realizada. 


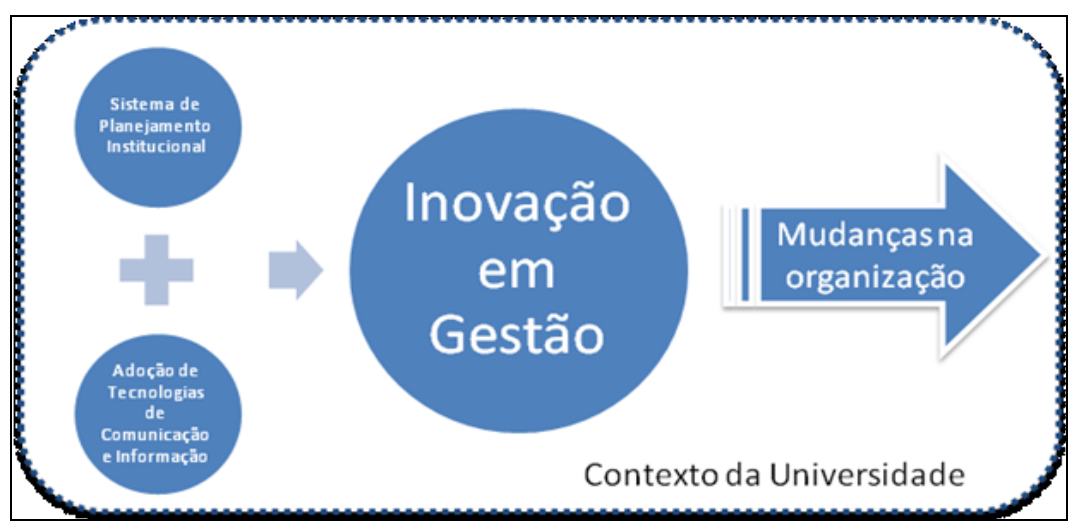

Figura 1 Elementos de observação da análise realizada. Fonte: Elaborado pelos autores.

Desse modo, este estudo de natureza descritiva apresenta a PGE da instituição de ensino superior, descrevendo como essa ferramenta alinhou-se ao processo de planejamento, orçamento e avaliação e possibilitou que a instituição superasse três grandes demandas: transparência das informações, organização virtual do planejamento - superando as barreiras geográficas e organizacionais - e alinhamento das ações com os recursos humanos e financeiros.

\section{FUNDAMENTAÇÃO TEÓRICA}

\subsection{INOVAÇÃO EM GESTÃO}

A inovação em gestão vem sendo investigada por autores como Mol e Birkinshaw (2009), que a consideram positivamente associada à performance da empresa. Para o aporte sobre este tópico, remete-se ao conceito de Hamel (2006) que a conceitua como a inovação dos princípios e processos gerenciais que de fato transformam as práticas das tarefas dos executivos e as maneiras como elas são realizadas. Birknshaw, Hamel e Mol (2005) a descrevem como a implementação de uma nova prática, processo ou estrutura de gestão que altere significantemente a maneira de como esta é desenvolvida e favorece a organização a atingir os seus objetivos. A inovação em gestão implementada pode atingir um baixo ou amplo escopo e de baixa ou alta profundidade em relação aos princípios vigentes. Nesta lógica, quando uma mudança corresponde a uma mudança profunda nos princípios de toda a organização, pode gerar impactos nos modelos mentais da organização. Sob esse ponto de vista, a inovação de paradigma, ao ser considerada como uma mudança no modelo mental da 
organização (TIDD, BESSANT E PAVITT 2005), pode ser verificada de forma incremental ou radical.

De fato, qualquer mudança ocorrida e que conduza para a inovação em gestão é fruto de um processo. Birkinshaw e Mol (2006) estabelecem um modelo para o processo de inovação em Gestão. O primeiro elemento é a insatisfação com o status quo da organização, uma percepção tal como a citada por autores de mudança organizacional, como Kotter e Kohen (2002) que a descrevem como senso de urgência. O segundo elemento é a inspiração de fontes externas à organização. $O$ terceiro elemento diz respeito propriamente à invenção da prática, processo ou estrutura, e que passará por uma validação interna das expectativas da organização e por uma validação externa, como a aprovação de um observador independente . O último elemento é a difusão, quando esta prática passa a ser alvo de benchmark de demais organizações ou estudos. Ainda, Hamel (2006) aponta que em organizações de grande porte, tal como a IES investigada neste estudo, não há possibilidade de mudar as ações dos gestores, tal como o estabelecimento de prioridades, de um modo direto; portanto, faz-se necessária uma intervenção no sentido de transformar os processos que regem o trabalho destes gestores. No caso do uso de novas tecnologias, as empresas podem usar essas ferramentas para reforçar antigos hábitos gerenciais. Neste sentido, a adoção de uma tecnologia de informação deve estar precedida de uma renovação do processo de negócio.

Tais considerações, na medida em que estabelecem a adoção de tecnologias da informação alinhadas a processos que estabeleçam a coerência do sistema, convergem para o conceito descrito na seção seguinte, sobre Inteligência Distribuída.

\subsection{INTELIGÊNCIA DISTRIBUÍDA}

Conforme Mattos (2005), os recursos de informática são utilizados para aquisição de dados operacionais da empresa, e usados na produção de informações e geração de conhecimentos para a tomada de decisão; tais recursos constituem-se em tecnologias de informação e comunicação, e permeiam todas as áreas funcionais da organização. Entretanto, o hardware e o software são ferramentas de apoio, e é necessário que a organização perceba um sentido na sua utilização. Quando a aplicação desses sistemas de informação é de suporte a uma rede, para sustentar a distribuição de informações estruturadas, a abordagem de inteligência distribuída torna-se necessária. Tal abordagem tem sua origem na escola francesa de sistemas de informação estratégica com a obra de Tardieu e Guthman (1992) sobre o 
Triângulo estratégico - estratégia, estrutura e tecnologia da informação, o que suscitou uma maior atenção à teoria da organização inteligente (BARTOLI e LE MOIGNE, 1996) e nela o conceito de inteligência distribuída (FORGET e POLYCARPE, 1997; LEVY, 1999). Mais recentemente, alguns trabalhos, como o de Bonifácio, Bouquet e Manzardo (2000) apresentam o conceito de inteligência distribuída como um paradigma emergente na gestão do conhecimento, apoiando-se na idéia de que o conhecimento é sempre e irredutivelmente distribuído em múltiplos contextos de produção de conhecimento (pessoas, grupos, períodos de tempo e localização espacial, e assim por diante) e, portanto, não pode, em geral, ser simplesmente organizado em uma estrutura única, compartilhada e coerente.

Nesta mesma linha, Fachinelli et al. (2007), fundamentam que estabelecer uma rede é, sobretudo, dotar um espaço de uma linguagem que confira uma unidade de sentido e seja adequada para ser reconhecida. Ou seja, há uma ordem estável de signos em determinado espaço que orientam os movimentos. Aplicados no contexto do presente trabalho, tais conceitos indicam que, uma Plataforma de Gestão Estratégica pode auxiliar na interpretação semântica e cognitiva para os diferentes elementos da rede de planejamento, no caso as unidades acadêmicas, conferindo assim uma unidade de sentido ao Planejamento Institucional. O desempenho de uma rede dependerá de atributos fundamentais, como a conectividade, que é a capacidade de facilitar a comunicação sem ruídos entre os componentes, e a coerência, na qual há um interesse compartilhado entre o objetivo da rede e seus componentes (FACHINELLI et al 2007). A coerência, neste caso, é realizada pelo Sistema de Planejamento Institucional, que atua como o senso de norte dos componentes da rede, enquanto a conectividade é realizada pela Plataforma de Gestão Estratégica, e busca, portanto, facilitar a comunicação entre as unidades e pró-reitorias, a respeito do planejamento. Este conjunto possibilita, portanto, atribuir sentido ao contexto do Sistema de Planejamento Institucional. A figura-conceito 2 representa a articulação semântica realizada pela Plataforma de Gestão Estratégica, na medida em que possibilita a estruturação das informações. Dessa maneira, o contexto colaborativo possibilita a interação de informações orientadas para uma finalidade comum (FACHINELLI et al. 2007). O dispositivo de coerência principal é o Plano de Desenvolvimento Institucional e é reforçado pelas reuniões de assessoria realizadas pela Pró-Reitoria de Planejamento e Desenvolvimento Institucional, reforçando a comunicação sobre o alinhamento e buscando envolvimento no processo, adotando estratégias, por exemplo, de visitas locais em cada unidade. Seminários periódicos também são realizados 
para a manutenção da coerência. Estas, portanto, constituem-se nas ações presenciais. O segundo aspecto diz respeito à conectividade, que é realizada em função da plataforma tecnológica; ela possibilita a interação entre as pessoas e as informações do Sistema de Planejamento Institucional. Desse modo, tanto os dispositivos de conectividade (PGE), quanto os de coerência (assessoria), permitem que a inteligência seja distribuída por todas as unidades, e, portanto, haja uma maior assimilação a respeito do Sistema de Planejamento Institucional.

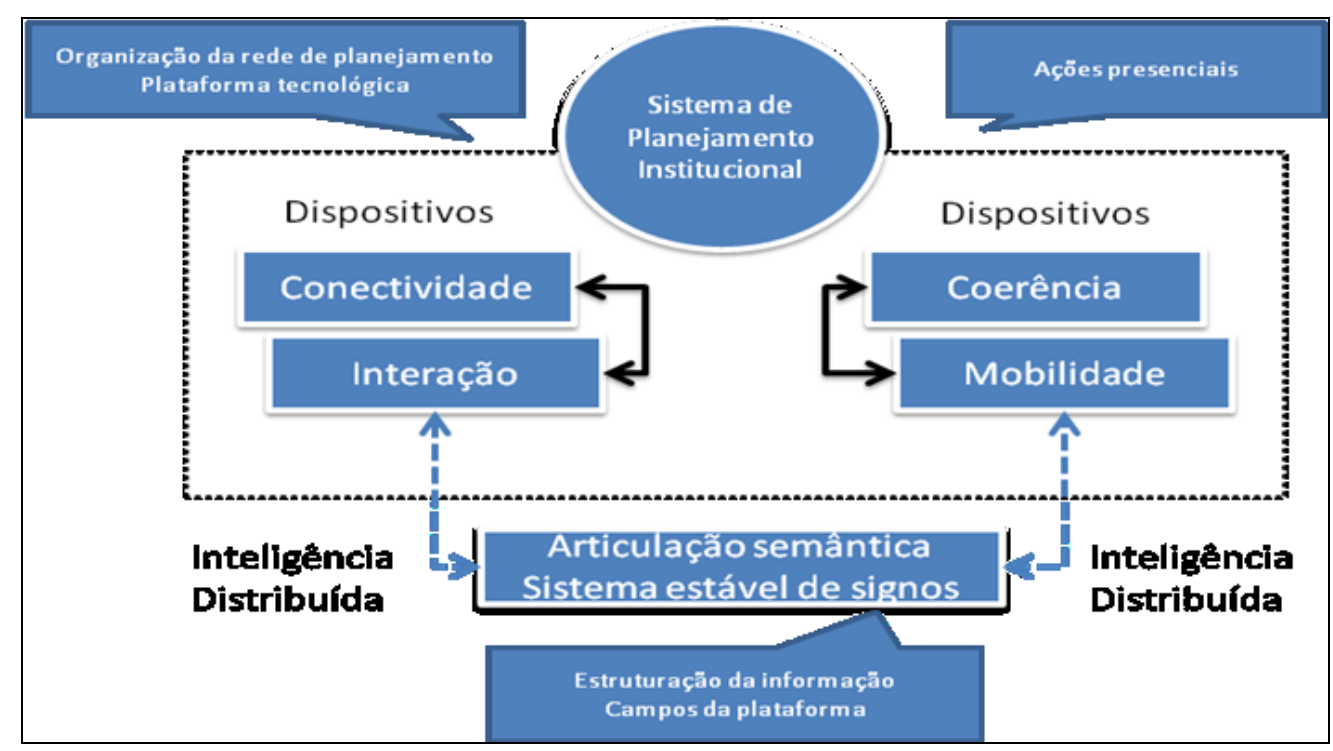

Figura 2 Dispositivos de inteligência distribuída.

Fonte: Adaptado de Fachinelli et al. (2007).

Em relação à conectividade, cabe contextualizar que a IES tem organizado o Sistema de Planejamento Institucional a partir do qual emergem duas categorias de objetivos, os denominados institucionais e os da unidade. Os primeiros são aqueles executados com uma pró-reitoria em conjunto com a unidade acadêmica, enquanto os segundos são aqueles realizados pela unidade acadêmica com autonomia nos seus investimentos. Portanto, verificase que a PPDI exerce um papel de gestão central do Sistema de Planejamento Institucional, conectada a todas as instâncias, sejam pró-reitorias ou unidades acadêmicas. As unidades, por sua vez, estabelecem interface com a PPDI, em função do SPI e com as demais pró-reitorias, em função dos objetivos institucionais. 


\subsection{PLANEJAMENTO EM INSTITUIÇÕES DE ENSINO SUPERIOR}

A regulamentação do Plano de Desenvolvimento Institucional (PDI), de acordo com o escopo do Sistema Nacional de Avaliação da Educação Superior (SINAES), tem exigido das IES a elaboração de um planejamento a médio prazo, num horizonte de 5 anos. Entretanto, Segenreich (2005) questiona até que ponto o plano é aplicado como uma ferramenta de gestão, ou para cumprimentos normativos. O desafio das instituições, portanto, é dar conta dos eixos temáticos obrigatórios do plano, ao mesmo tempo em que o PDI se legitime como uma ferramenta flexível de orientação dos planos institucionais. A constatação de que o instrumento somente será assumido caso seja construído pelos seus atores mediante um modelo de avaliação de quarta geração, ou seja, avaliação por negociação contínua, revela que a dinâmica do processo de construção e execução do PDI deve ser internalizado como um processo da instituição (SEGENREICH, 2005). A complexidade de uma organização acadêmica indica que um planejamento do tipo top-down, quando parte da reitoria para as unidades ou botton-up, que consiste no processo inverso não são as mais adequadas. Uma abordagem do processo de planejamento denominada de "W" (COSTA, 2007; KACHANER ET AL, 2008) na qual há movimentos de definições e feedback, intercalando momentos de top-down (definições institucionais) e botton-up (discussão e legitimação das definições) que envolvem toda a comunidade acadêmica (COSTA, 2007; KACHANER et al, 2008) parece ser mais adequada quando se trata de organizações complexas. Entretanto, o processo é mais demorado, o que entra em conflito com os prazos de entrega para a submissão do PDI, mas possui consonância com a dinâmica proposta pelo Conselho de Pró-Reitores de Planejamento e Administração das Universidades Federais (FORPLAD, 1995).

\section{METODOLOGIA}

\subsection{O CONTEXTO E O OBJETO DE ESTUDO}

A instituição de ensino superior investigada é de caráter comunitário e regional pela sua abrangência de 70 municípios. Sua área de atuação é formada pelas atividades em ensino, pesquisa e extensão, sendo caracterizada predominantemente pelo ensino de graduação, perfil que vêm sendo alterado para pesquisa e extensão há cerca de dois anos, em virtude das demandas do ambiente externo e de decisões institucionais. Atualmente possui cerca de 37.000 alunos, 1.100 docentes e 900 funcionários. Localizada na Serra Gaúcha, a instituição possui uma estrutura multicampi, com unidades acadêmicas instaladas em 9 cidades, sendo 
em Caxias do Sul a sede. Esta estrutura organizacional, apesar das vantagens de proximidade com a comunidade externa, apresenta os seguintes desafios: Transparência das informações: considerando que a administração é centralizada em Caxias do Sul, sempre houve queixas da comunidade acadêmica a respeito do tempo para que as informações, tanto administrativas quanto diretivas fossem de conhecimento das demais unidades; Descontinuidades do planejamento: a IES já tentou implementar planejamento estratégico, inclusive com o suporte de consultorias externas. Entretanto, o processo sempre sofreu descontinuidades até 2005, apesar de a instituição ter se expandido significantemente neste período; Alinhamento com os recursos: uma falha a ser considerada no planejamento, é quando não há liberação de recursos humanos e financeiros para a execução dos objetivos. Antes da implantação do Sistema de Planejamento da IES, uma das questões que impactava a descontinuidade era a falta de vínculo com o orçamento. Neste contexto, delimita-se como objeto de estudo a abordagem desenvolvida pela IES, que consiste na integração do seu Sistema de Planejamento Institucional com a adoção de tecnologias de Informação e Comunicação.

\subsection{MÉTODO DE PESQUISA}

Tendo em vista o caráter descritivo e qualitativo desta pesquisa, o método empregado foi o estudo de caso, conforme exposto por Yin (2001). É pertinente ressaltar que este método, conforme Oliveira, Maçada e Goldoni (2006), tem sido o mais adotado atualmente para pesquisas na área de Sistemas de Informação, em função de ainda se estar buscando um melhor entendimento dos fenômenos investigados. O estudo contemplou também uma estratégia de triangulação, que de acordo com Stake (1995) consiste em protocolos utilizados para assegurar a confiabilidade e explicações alternativas. Assim, para operacionalizar esta estratégia, Denzin (2009) propôs quatro tipos de mecanismos de triangulação, os quais foram compreendidos nesta investigação da seguinte maneira:

a) das fontes de dados, os quais consistem no confronto de diferentes fontes: neste caso, por tratar-se de fontes documentais, a origem das informações é a própria organização;

b) do investigador, onde os entrevistadores ou observadores diferentes procuram detectar viés da influência do investigador principal: os autores deste estudo, além de pesquisadores da área de Administração, possuem um nível de inserção gradual em relação ao fenômeno analisado; o pesquisador 1 participou do processo de implantação, o que possibilitou melhor entendimento do contexto e maior acesso aos entrevistados e dados; os 
pesquisadores 2 e 3 não participaram do processo de implantação do Sistema, mantendo, portanto, um olhar externo aos eventos e minimizando quaisquer vieses das análises.

c) da teoria, a partir de perspectivas teóricas e hipóteses diferentes: a proposta deste estudo parte do modelo de Inovação em Gestão, de Inteligência Distribuída e de Gestão Estratégica em IES, possibilitando uma visão multidimensional do fenômeno.

d) da metodologia, a partir do cruzamento das fontes primárias e secundárias: para esta pesquisa, o cruzamento entre as informações dos entrevistados e da pesquisa documental foi possível a partir da coleta de informações das duas fontes, sendo o procedimento da coleta de fonte primária descrito a seguir; para efeito de análise do conjunto de informações, observa-se que as fontes secundárias representam em torno de $70 \%$ do conteúdo utilizado para a descrição do fenômeno, em termos de importância relativa, enquanto os $30 \%$ restante são em função dos dados primários.

Para a coleta de dados com os entrevistados, foi feito uso do método de método de entrevistas narrativas (storytelling), o qual possibilita a extração de informações subjacentes ao tema de estudo, e permite que se compreenda as perspectivas dos participantes sobre o fenômeno em questão na etapa de coleta de dados. Para esta situação, foi questionado: "conte uma história sobre uma inovação que tenha ocorrido na Universidade", neste caso, para o Pró-Reitor de Planejamento e Desenvolvimento Institucional da Instituição. Os relatos evidenciaram, conforme observado na descrição das análises, o período de um ano desde a formalização do início da implantação do Sistema. Para a supervisora e assessora da Divisão de Planejamento, foi realizada uma complementação de informações, a partir de uma entrevista não estruturada, resgatando elementos que emergiram na entrevista narrativa.

Em relação à análise do conteúdo material, a partir da transcrição, foram identificados os elementos estruturais superiores, os elementos estruturais detalhados, e o resumo do conteúdo, a partir do segmento narrativo, o CNS (troca de segmento), a descrição e a análise (apêndice I).

\section{DESENVOLVIMENTO DA PESQUISA: ESTUDO DE CASO DA IES}

\subsection{ANTECEDENTES E MOTIVAÇÕES PARA A ADOÇÃO DE TI NO PLANEJAMENTO}

Conforme o Pró-Reitor de Planejamento e Desenvolvimento Institucional, o início do projeto de alinhamento de um sistema de gestão estratégica com o planejamento institucional 
na IES deve-se à experiência bem sucedida da adoção de um portal na web como ferramenta de apoio para a elaboração do relatório da Auto-Avaliação Institucional (FACHINELLI et al. 2007). Na medida em que o sistema atribuiu significado para o contexto dos sujeitos envolvidos no processo, verificou-se que o uso de ferramentas de TI teria condições de ser uma estratégia de dinamização do fluxo de informações distribuídas entre as redes. O documento da Auto-Avaliação Institucional sintetiza o diagnóstico interno da instituição, e em virtude deste trabalho, foi possível, e com êxito, superar as barreiras geográficas e realizar um gerenciamento eficaz das informações que serviriam, no futuro, de premissas para a elaboração do planejamento estratégico.

\subsection{BREVE CONTEXTO HISTÓRICO DO PLANEJAMENTO NA UNIVERSIDADE}

O SPI da Universidade estudada é fruto de um contexto mais amplo: a universidade desenvolveu seu primeiro planejamento estratégico em 1995, com o auxilio de uma assessoria externa. A partir daquele momento, foram desenvolvidas a Visão, Missão e Princípios da instituição; entretanto, o desdobramento de objetivos e seu desenvolvimento não manteve um padrão consistente ao longo dos anos, inclusive por características centralizadoras da própria gestão, mas fundamentalmente, por dois aspectos essenciais: a) a alocação de recursos financeiros; b) execução do planejamento, o que demanda uma gestão informacional eficiente para o acompanhamento.

Com o final da Auto-avaliação, em 2005, foi iniciado o processo de revisão das bases do planejamento estratégico da instituição, reavaliando seu foco, visão, missão e princípios, suas diretrizes e seus objetivos institucionais, no sentido de aprofundar as bases conceituais e os grandes referenciais norteadores da ação acadêmica. Naquele momento, a comunidade acadêmica foi envolvida, entretanto, o processo não avançou da mesma maneira como em 1995, tendo em vista que houve uma troca da gestão em março de 2006. No início de 2007, com uma nova equipe interna de planejamento, foi diagnosticado que havia, na instituição, cinco diferentes documentos institucionais que atuavam como norteadores das ações. Entre eles estavam o documento com as Bases do planejamento estratégico, desenvolvidas em 2006; o Relatório da avaliação institucional, finalizado em 2006; a Carta-compromisso do Reitor, apresentada em março de 2006; o Plano de gestão da Reitoria, desenvolvido em 2006 e o Plano de Desenvolvimento Institucional, em elaboração entre outubro de 2006 e março de 2007. Para eliminar a redundância foi realizado um estudo de convergência dessas 
informações, utilizando-se de uma metodologia de análise qualitativa envolvendo mapas conceituais para verificar a relação entre os elementos de cada documento. Observou-se que havia uma convergência significativa entre as propostas, e portanto, foi elaborado um esboço do que seria o alinhamento institucional, que consiste no arcabouço de diretrizes e objetivos. Tais informações foram validadas no nível institucional e incorporadas ao PDI, que serviu como o instrumento de formalização e definição dos norteadores da IES. Este foi um marco político importante para a consolidação do SPI.

O passo seguinte, após a institucionalização do PDI, seria o início da implantação do Sistema de Planejamento da Universidade. O SPI já continha em sua base cinco pressupostos, que seriam: a) a integração entre os elementos (planejamento, orçamento, avaliação); b) fundamentação na comunidade acadêmica para validação dos norteadores; c) uso de tecnologias de informação e inteligência estratégica como suporte aos processos; d) apoio das redes sociais para os elementos (planejamento, orçamento, avaliação), estabelecendo canais de comunicação; e) validação dos planos mediante um comitê, cujo papel é de analisar a consistência e convergência dos objetivos desenvolvidos pelas unidades.

A figura 3, que trata da primeira versão do modelo, apresenta sua lógica de funcionamento. Ele estabelece, a sua esquerda, que todo o planejamento teria suporte de sistemas de informação, papel que viria a ser assumido pela Plataforma de Gestão Estratégica. Da mesma maneira, a IES vem investindo em Tecnologias de Informação e Comunicação para a sua gestão administrativa e, portanto, ferramentas de Business Intelligence e Robôs de busca fazem parte dos sistemas de informação que contribuem para o planejamento, já que eles fornecem suporte para as análises interna e externa. Ao lado direito do modelo, constituise a avaliação institucional, que é a consolidação dos diagnósticos da instituição, em todos os níveis, e de escopos acadêmicos a administrativos. A avaliação também é suportada pelos sistemas de informação (FACHINELLI et al. 2007), mas sua plataforma tecnológica passou por uma migração após 2006, sendo realizada no mesmo sistema de gestão estratégica, inclusive como uma estratégia para que a comunidade percebesse que tanto o planejamento quanto a avaliação fazem parte do mesmo processo. O eixo central do modelo indica os desdobramentos, a partir do PDI, nos quais a instituição trabalharia o planejamento em nível tático, o que significa o desenvolvimento dos objetivos das pró-reitorias e das unidades acadêmicas. A gestão das informações e do conhecimento, portanto é vista como um elemento unificador deste sistema. 


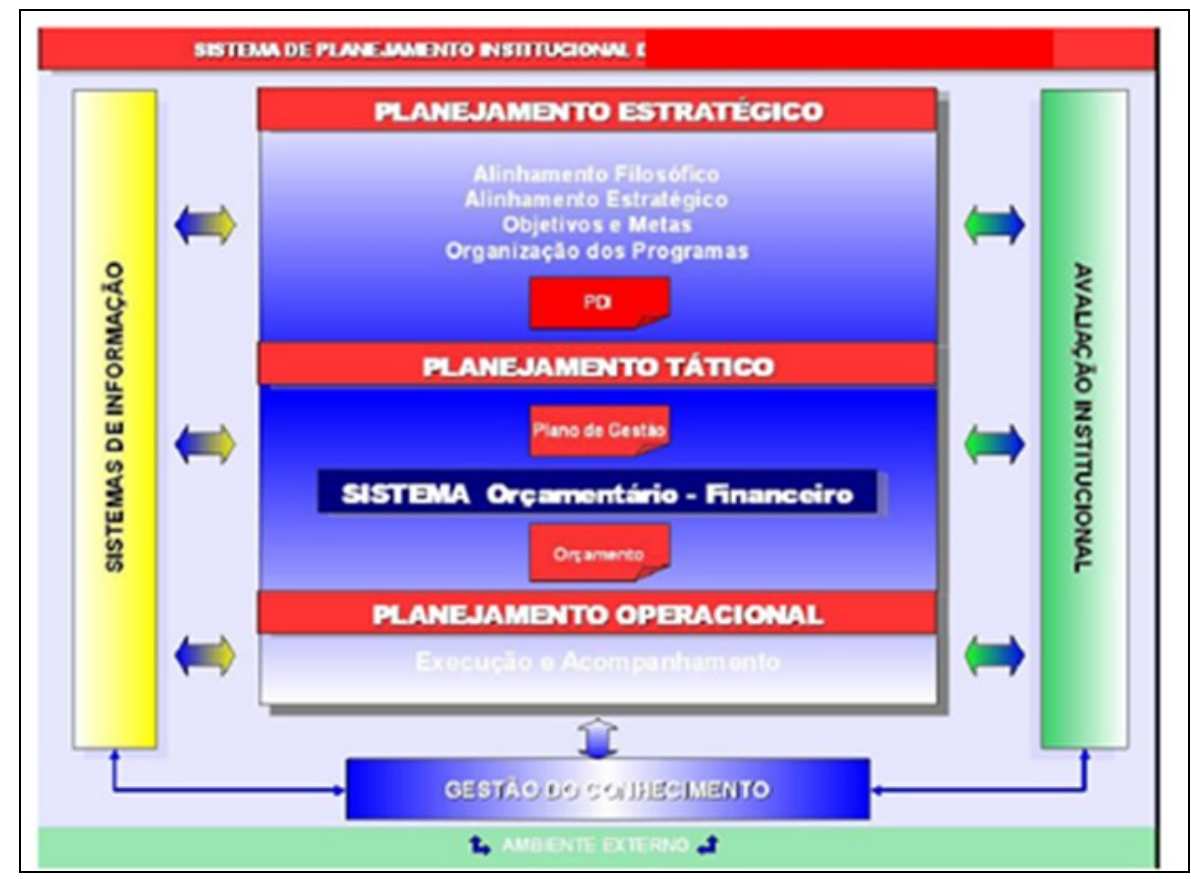

Figura 3 Modelo do Sistema de Planejamento Institucional. Fonte: Pró-Reitoria de Planejamento e Desenvolvimento Institucional.

O modelo apresentado, ficou vigente até o final do primeiro semestre de 2008. De acordo com a PPDI, um modelo evoluído, fruto das aprendizagens decorridas desde o início da implantação, foi institucionalizado no início de 2009. Em função da pesquisa documental, foram observados relatórios do ano de 2000 que demonstram que níveis semelhantes já haviam sido atingidos, ou seja, houve, em determinada época, a definição de objetivos das unidades acadêmicas, mas cujo planejamento não foi executado. No SPI, entretanto, alguns aspectos tornaram-se diferenciais e possibilitaram que o processo tivesse continuidade, mas sobretudo, legitimidade e credibilidade: $\mathrm{O}$ orçamento das unidades não mais seguiria uma negociação política e desprovida de critérios, como ocorria nos demais anos. Estabeleceu-se, portanto, com auxílio do Sistema de Informações Gerenciais (BI), indicadores de porte e de desempenho das unidades; foi definido o rateio dos investimentos para cada unidade, de acordo com os indicadores; Esse orçamento estaria descentralizado. Desse modo, a unidade poderia fazer uso dessas verbas desde que fossem aplicadas em objetivos de seu planejamento. Até então a instituição possuía dois grandes sistemas informatizados que contribuíam para o planejamento: o sistema de informações gerenciais e um sistema de orçamento, que consiste num portal em que as unidades programam os recursos necessários para o ano. Entretanto, segundo a fala dos entrevistados, todo o orçamento era superestimado, 
por não haver um planejamento que o balizasse e por questões culturais da instituição, em que se solicitava em excesso já prevendo os cortes orçamentários.

Portanto, a PPDI identificou que era necessária uma plataforma que atuasse como ponto central desse sistema e tivesse um papel de estruturação e gestão das informações do planejamento, mas que atuasse de uma forma descentralizada, de modo a compatibilizar com a organização em rede das unidades.

\subsection{INTRODUÇÃO DO SISTEMA INFORMATIZADO DE GESTÃO ESTRATÉGICA}

A instituição realizou um levantamento entre diversas soluções concorrentes, e adotando os parâmetros de aquisição (linguagem do sistema, localização do suporte da empresa, histórico, análise financeira do investimento, especificações do produto, compatibilidade com a metodologia) selecionou uma plataforma desenvolvida em linguagem Java, o que diminuiu significativamente o investimento. Ela atua com um aplicativo servidor instalado no data warehouse da instituição, centralizando o banco de dados, e por meio da rede interna, os usuários acessam o módulo-cliente, que contém a interface de trabalho.

O primeiro ganho em gestão da informação viria, portanto, com a centralização dos dados: um dos aspectos que havia antes de 2007 era a dificuldade de manter as informações sincronizadas, tendo em vista que se trabalhava com planilhas informatizadas. Portanto, era comum ter mais do que uma versão dos planos nas mãos das pró-reitorias. Nesse sentido, um princípio de Gerenciamento Eletrônico de Documentos, o versionamento, estava sendo introduzido para as informações do planejamento.

O conceito deste sistema é atuar por modelos, que correspondem a arquivos nos quais toda estrutura do planejamento é abrangida, envolvendo os indicadores, objetivos e planos de ação. Esses modelos, entretanto, estão tecnicamente ligados a um modelo "pai” e conceitualmente ligados às diretrizes e objetivos institucionais definidos no Plano de Desenvolvimento Institucional da IES. Isto representa que os gestores podem acompanhar quais objetivos cada unidade acadêmica está realizando para atender, por exemplo, uma diretriz maior de qualificação da educação continuada.

Essas informações estão estruturadas de uma forma visual, que possibilita aos gestores acadêmicos e aos envolvidos na rede do sistema de planejamento perceberem como suas iniciativas alinham-se aos objetivos da instituição. Conforme exposto por Fachinelli et al. (2007), definir uma rede é dotar um espaço de linguagem que confira um sentido e esteja apto 
para ser reconhecido. A equipe de planejamento tem registrado, portanto, que as unidades acadêmicas têm assimilado melhor o Sistema de Planejamento Institucional, pois este espaço construído fornece um sentido e facilita o reconhecimento do papel delas no contexto geral.

Conforme a equipe de implantação, as primeiras considerações acerca deste sistema eram de como ele realmente realizaria a estruturação dessas informações e, como conseqüência, essa visibilidade traria uma coordenação mais efetiva dos trabalhos e dos atores. De acordo com eles, as etapas desenvolvidas foram as seguintes:

a) avaliação da atual estrutura organizacional da instituição, que serviria de base para a replicação na Plataforma de Gestão Estratégica. Um aprendizado elencado por uma das assessoras do planejamento foi de que, mesmo com a estrutura atual mapeada, a modelagem na Plataforma gerou uma terceira forma de organização da universidade. A primeira delas corresponde à estrutura de centros de custo, que é o mapa da organização utilizado para a apropriação de receitas e despesas. A segunda era a estrutura de poder, que não correspondia a esse mapa organizacional. Um sistema de gestão deve estar alinhado com a estrutura organizacional, caso contrário, disfunções são geradas.

b) modelagem de uma estrutura que representasse o PDI. Ela foi considerada um dos marcos essenciais do SPI. Como existe um grande número de objetivos, foi criada uma estrutura-modelo denominada alinhamento, que continha todas as diretrizes e objetivos institucionais, validados pelos conselhos da universidade, e que serviria como "origem" dos demais modelos de cada unidade. Utilizando-se, portanto, da mesma lógica de versionamento, foi possível unificar a linguagem dos rumos que a instituição deveria seguir.

c) A terceira etapa envolveu o trabalho de campo, no qual as unidades acadêmicas foram assessoradas na definição de seus objetivos a curto prazo. Cada unidade acadêmica realizou um diagnóstico interno e externo, utilizando a metodologia SWOT e GUT, envolvendo os colegiados de curso, funcionários e alunos. O processo foi convergindo a ponto de que, com base nessas avaliações, a unidade priorizasse seus objetivos. Esta etapa, entretanto, não foi utilizada com o sistema informatizado, pois não havia tempo hábil para que os envolvidos das unidades se familiarizassem com ele. Desse modo, foram criados formulários com uma estrutura exata dos campos necessários para a PGE, campos estes já validados anteriormente pela equipe de planejamento como sendo adequados para a metodologia utilizada. O objetivo desta abordagem foi de que as pessoas pudessem 
reconhecer, ao iniciar o treinamento no sistema, que havia uma lógica entre o que elas realizaram presencialmente e o que estaria virtualmente no sistema.

d) A quarta etapa envolveu a introdução dessas informações no sistema, trabalho realizado pela equipe de planejamento. Nesse momento, foram criadas as categorizações de "objetivos institucionais", "objetivos táticos da unidade" e "objetivos táticos - horasdocente". Os primeiros respondiam a iniciativas que envolveriam as pró-reitorias, os segundos poderiam ser realizados pelas unidades e envolveriam investimentos financeiros; os terceiros também possuíam essa característica, mas demandavam apenas recursos humanos alocados em planilha. O sistema, neste sentido, possibilitava que o objetivo pudesse ser visualizado sob duas perspectivas: como estava alinhado ao PDI e em que categoria de recursos ele pertencia. A modelagem dessas informações no sistema representou um grande avanço, conforme relatado nas entrevistas, pois o número de informações geradas (objetivos definidos) foi muito grande (em torno de 160 objetivos), as decisões tomadas a respeito da categorização e dos objetivos aprovados só foram possíveis em função da facilidade de estruturação e recuperação dessas informações.

e) A etapa considerada mais significante foi a que possibilitou as unidades delimitarem um orçamento para seus objetivos. Cada unidade acadêmica seria avaliada por variáveis de porte, que representam a grandeza da mesma, e por variáveis de desempenho, que avaliam o resultado. Foram gerados indicadores que, com um tratamento estatístico, foram padronizados para as unidades e estes parâmetros serviram de critério para a alocação dos recursos institucionais para cada objetivo. Três mudanças organizacionais foram observadas nesta etapa: descentralização parcial do orçamento de investimentos; alocação profissional dos recursos; os investimentos passariam a ser balizados por um planejamento alinhado aos norteadores institucionais.

\subsection{ANÁLISE}

De acordo com a equipe do planejamento, tanto o Sistema de Planejamento Institucional quanto a Plataforma de Gestão Estratégica ainda tem como desafio maior vencer barreiras culturais da instituição, que se formaram como consequência das gestões centralizadas. Entretanto, eles observam que mudanças estão ocorrendo na organização, uma vez que as informações sobre o planejamento, o orçamento e a avaliação estão disponíveis para todos os componentes da rede de planejamento; estabeleceu-se uma organização virtual 
do processo, o que possibilita uma troca online das informações, superando as barreiras geográficas: um pró-reitor, por exemplo, tem condições de verificar a execução do objetivo de um determinado núcleo; mas o ponto principal foi a possibilidade dessa abordagem gerar uma organização de pessoas para o a execução dos objetivos, e uma coordenação dos recursos financeiros orientados para o planejamento. Sob o ponto de análise da inovação em gestão, é observado que melhorias foram introduzidas tanto em relação a processos como em relação à filosofia de gestão, como apontado por Hamel (2006). Dessa forma, com base nas falas registradas da equipe, buscou-se montar a figura 4, sistematizando as inovações introduzidas em função da implantação do SPI e da PGE.

\begin{tabular}{|c|c|c|}
\hline Aspecto & Antes da adoção & Após a adoção \\
\hline $\begin{array}{lr}\text { Acessibilidade } & \text { das } \\
\text { informações } & \text { do } \\
\text { planejamento } & \end{array}$ & Consulta aos responsáveis & $\begin{array}{l}\text { Qualquer unidade acadêmica tem acesso aos planos de seus pares. } \\
\text { Foi introduzida a possibilidade de acesso as informações em tempo } \\
\text { real. }\end{array}$ \\
\hline $\begin{array}{l}\text { Organização virtual } \\
\text { do planejamento }\end{array}$ & Inexistente. & $\begin{array}{l}\text { O planejamento, ainda que feito presencial, tem o suporte do } \\
\text { acompanhamento das execuções de forma online. Dessa maneira, os } \\
\text { gestores não precisam se deslocar até a sede para apresentação dos } \\
\text { resultados. Foi introduzida, portanto, uma nova forma de } \\
\text { comunicação que tem um ruído menor que os canais informais. }\end{array}$ \\
\hline $\begin{array}{l}\text { Alinhamento entre } \\
\text { planejamento } \\
\text { recursos }\end{array}$ & $\begin{array}{l}\text { O orçamento de investimentos era } \\
\text { realizado com base histórica, e sem } \\
\text { planejamento prévio. A liberação } \\
\text { das verbas dependia mais da } \\
\text { capacidade do diretor de centro } \\
\text { negociar politicamente com a } \\
\text { reitoria do que o próprio } \\
\text { desempenho do centro. }\end{array}$ & $\begin{array}{l}\text { Foi introduzida uma sistemática analítica de rateio das verbas. O } \\
\text { orçamento só poderá ser utilizado caso haja o planejamento } \\
\text { desenvolvido na plataforma. Dessa forma, observa-se uma } \\
\text { profissionalização do processo, com o estabelecimento de critérios } \\
\text { racionais para a locação dos recursos. O diretor de centro não têm } \\
\text { mais condições de negociar orçamento como acontecia anteriormente } \\
\text { à adoção. }\end{array}$ \\
\hline \begin{tabular}{l|l} 
Descentralização & I \\
parcial dos & c \\
investimentos
\end{tabular} & $\begin{array}{l}\text { Inexistente. A reitoria decidia onde } \\
\text { o orçamento deveria ser aplicado. }\end{array}$ & $\begin{array}{l}\text { Foi introduzida a possibilidade dos centros terem autonomia sobre a } \\
\text { suas verbas do rateio e na aplicação de seus objetivos táticos. }\end{array}$ \\
\hline Gestão estratégica & $\begin{array}{lll}\text { Os objetivos propostos } & \text { eram } \\
\text { descontinuados } & \text { após um } & \text { curto } \\
\text { período de tempo. }\end{array}$ & $\begin{array}{l}\text { Contínua: os planos propostos vêm mantendo consistência de } \\
\text { planejamento e execução, sendo revisados quando necessário, em } \\
\text { função da introdução do SPI. As informações geradas e a própria } \\
\text { maturidade que o processo vêm adquirindo estão possibilitando a } \\
\text { instituição a construir um posicionamento estratégico }\end{array}$ \\
\hline Ciclo PDCA & $\begin{array}{|llr|}\text { Os objetivos, } & \text { por } & \text { serem } \\
\text { descontinuados, } & \text { não } & \text { eram } \\
\text { avaliados. } & & \end{array}$ & $\begin{array}{l}\text { A instituição implantou em seu calendário o processo de análise } \\
\text { crítica dos objetivos, que realizado via a plataforma, cria uma base de } \\
\text { conhecimento acerca do andamento e dificuldades enfrentadas nos } \\
\text { planos propostos. }\end{array}$ \\
\hline $\begin{array}{l}\text { Uso da ferramenta e } \\
\text { tomada de decisão }\end{array}$ & $\begin{array}{l}\text { Inexistente. Os gestores não faziam } \\
\text { uso de tecnologias de informação e } \\
\text { comunicação para este fim. }\end{array}$ & $\begin{array}{l}\text { Os pró-reitores e grupos estratégicos já utilizam a ferramenta ou seus } \\
\text { relatórios nas reuniões, atribuindo um caráter analítico de tomada de } \\
\text { decisão, em virtude da introdução da responsabilidade pelas ações, } \\
\text { definida na metodologia e acompanhada pela plataforma. }\end{array}$ \\
\hline Aprendizagem & Básica & $\begin{array}{l}\text { Observa-se que a instituição estabeleceu um marco de observação, e } \\
\text { busca introduzir inovações tanto na ferramenta quanto na } \\
\text { metodologia. Em relação às unidades acadêmicas, foi relatado que a } \\
\text { atribuição de sentido proporcionada por essa abordagem está fazendo } \\
\text { com que elas entendam o planejamento, o orçamento e a avaliação } \\
\text { como um sistema integrado. }\end{array}$ \\
\hline
\end{tabular}

Figura 4 Síntese das inovações em gestão observadas.

Fonte: Elaborado pelos autores, com base nos dados coletados. 


\section{CONSIDERAÇÕES FINAIS}

O objetivo deste estudo foi compreender como uma Instituição de Ensino Superior articula a gestão da Tecnologia da Informação com seu Sistema de Planejamento, e quais mudanças organizacionais decorreram desta abordagem. De fato, o êxito desta articulação, no contexto investigado, deve-se ao estabelecimento de dispositivos de conectividade e de coerência que permitiram tanto o dinamismo do sistema como o estabelecimento de significados comuns ao longo de todo o processo. A implantação de um software de gestão estratégica, sem estar amparado por processos e bases metodológicas implicaria numa plataforma estática, sem apropriação pelas pessoas desta organização. Já a implantação de uma metodologia de Gestão Estratégica (Sistema de Planejamento Institucional), sem o amparo da Tecnologia da Informação, não possibilita a gestão da informação e a estruturação dos signos associados a este processo. Este aspecto é fundamental numa organização de complexidade como uma Instituição de Ensino Superior, uma vez que na dimensão do Planejamento, sua estrutura e interações constituem-se numa rede.

Ainda, a partir de uma visão sistêmica, ao somar-se a implantação do Sistema de Planejamento Institucional com a adoção de TI, verificou-se que inovações incrementais na gestão foram desencadeadas, o que sugere a influência desta abordagem na geração de mudanças organizacionais.

Para este contexto específico, as informações analisadas nos apresentam uma perspectiva de que esta inovação em gestão abrangeu os elementos identificados por Birknshaw e Mol (2006), no que se refere ao seu processo: a) a insatisfação com o status quo da gestão da informação sobre o planejamento estratégico; b) a inspiração, neste caso, no projeto da avaliação institucional; c) a invenção propriamente dita, que envolveu a concepção do modelo; d) a validação interna, por meio da internalização do processo no calendário Institucional de planejamento, orçamento e avaliação, e como uma prática da organização; e) a validação externa, por meio de visitas de outras Instituições de Ensino.

Ressalta-se também que os elementos desenvolvidos ao longo deste estudo indicam que esta inovação em gestão tem uma alta abrangência, pois afeta todas as partes do sistema organizacional, tomando-se como base o modelo de Birknshaw, Hamel e Mol (2005). Contudo, não é possível afirmar qual a profundidade desta inovação, uma vez que este estudo, em função de suas limitações, não utilizou abordagens que possibilitassem uma mensuração mais consistente sobre a mudança dos princípios fundamentais da gestão desta organização. 
Nesta perspectiva, sugere-se que a investigação seja ampliada para demais instituições de ensino superior, de contexto semelhante, e que tenham desenvolvido experiências de integração do planejamento estratégico com a tecnologia da informação. Ainda, tendo em vista que uma inovação incremental em gestão necessita de tempo e de amadurecimento para consolidar-se, um novo estudo longitudinal, nesta mesma Instituição, buscando uma investigação mais profunda sobre a mudança nos princípios de gestão, também trará contribuições fundamentais no campo da inovação em gestão.

\section{REFERÊNCIAS}

BAKOS, Y. J.; T. M. E. Information technology and corporate strategy: a research perspective. MIS Quarterly, Jun. 1986.

BARTOLI, A.; LE MOIGNE J.L. Organisation Intelligent et Système d'Information Stratégique. Paris. Economica, 1996.

BENBASAT, I.; GOLDSTEIN, D. K.; MEAD, M. The case research strategy in studies of information systems. MIS Quarterly, V.11, N.3, p.369-386, set. 1987.

BIRKINSHAW J; MOL M J. How management innovation happens. MIT Sloan Management Review. Vol 47:4, 2006. p. 81-88

BIRKINSHAW, J.; MOL, M. J.; HAMEL, G.Management Innovation. Advanced Institute of Management. Research Paper No. 021,2005, Disponível em http://ssrn.com/abstract=1306981

BOJE, D. M. Narrative methods for organizational and communication research. London: Sage, 2001.

BONIFACIO, M.;BOUQUET, P.; MANZARDO A.. AAAI Technical Report SS-00-03, AAAI, 2000. DISPONÍVEL EM http://www.aaai.org/Papers/Symposia/Spring/2000/SS-0003/SS00-03-011.pdf

BRASIL. Decreto No 5.773, DE 9 DE MAIO DE 2006. Dispõe sobre o exercício das funções de regulação, supervisão e avaliação de instituições de educação superior e cursos superiores de graduação e seqüenciais no sistema federal de ensino. Diário oficial da República Federativa do Brasil, Brasília. 10 de julho de 2006.

BRODBECK, A. F., HOPPEN, N.. OLIVEIRA, A. S. MAJDENBAUMN, Azriel. Alignment between organizational and information systems objectives : multiple case studies. REAdSpecial Issue 36 Vol. 9 No. 6, Nov-Dec 2003

COSTA, E. A. Gestão Estratégica: da empresa que temos para a empresa que queremos. São Paulo. Editora Saraiva, 2007. 
CZARNIAWSKA, B.. Narratives, Interviews and Organizations. In: Handbook Handbook of Interview Research: context and method. Jaber F. Gubriun and James A. Holstein. Sage Publications, 2001.

DENZIN, N. The Research Act: A Theoretical Introduction to Sociological methods. Prentice Hall College Div, 2009.

ELIOTT, J. Using Narrative in Social Research.: qualitative and quantitative Approaches. SAGE Publications, 2005.

FACHINELI, A .C; OLIVEIRA, R. L; CASA, M. .E. La organización de la inteligência distribuída como estratégia de desarrollo baseado em conocimiento. Capítulo do livro Regiones Iberoamericanas del conocimiento: experiências de desarollo regional. San Sebastian: Universidade de Deusto, 2007.

FORGET P. P. “G. La Red y el infinito”. Lisboa: Instituto Piaget,, pag.16, 1997.

FORPLAD - Fórum Nacional de Pró-Reitores de Planejamento e Administração.

Planejamento estratégico em instituições federais de Ensino superior: proposta de processo participativo, 2008. Disponível em http://www2.uel.br/pei/download/FORPLAD.pdf

HAMEL, G. O laboratório de inovação em gestão. HSM Management. n.58, a.10, v.5, pág 120-126, set./out. 2006.

KOTTER, J. P.; COHEN, D. S. O Coração da mudança: transformando empresas com a força das emoções. Rio de Janeiro: Campus, 2002. 202p.

LÉVY, P. A. Inteligência coletiva: por uma antropologia do ciberespaço. São Paulo: Edições Loyola, 1999.

MATTOS, J. R.L. Gestão de Tecnologia e Inovação: uma abordagem prática /[João Roberto Loureiro de matos, Leonam dos Santos Guimarães]. São Paulo: Saraiva, 2005.

MEYER Jr. V. Teoria e Prática da Gestão Universitária. Cadernos - Centro Universitário São Camilo. São Paulo, v.4, n.1. 1998, p. 49-59.

MINTZBERG, H.; AHLSTRAND, B.; LAMPEL, J. Safári de estratégia: um roteiro pela selva do planejamento estratégico.Porto Alegre: Bookman, 2000.

MOL M.J., BIRKINSHAW J. The sources of management innovation: When firms introduce new management practices, Journal of Business Research. Volume 62, Issue 12, December 2009, p. 1269-1280.

MORAES, Giseli Diniz de Almeida. TERENCE, Ana Cláudia Fernandes. FILHO, Edmundo Escrivão. Information technology as a support to the strategic management of information in small businesses. Journal of Information Systems and Technology Management. Vol. 1, No. 1, 2004, pp. 28-44 
OLIVEIRA, M.. MAÇADA, A. C. G.. GOLDONI, V. Análise da Aplicação do Método Estudo de Caso na Área de Sistemas de Informação. Encontro Nacional de Pesquisa em Administração. Salvador, 2006.

REZENDE, D. A. Alinhamento estratégico da ecnologia da informação ao business plan: contribuição para a inteligência empresarial das organizações. REAd. Edição 31 Vol. 9 No. 1 , jan-fev 2003.

RIESSMAN. C. K.. Analysis of personal narratives. In: Handbook of Interview Research: context and method. Jaber F. Gubriun and James A. Holstein. Sage Publications, 2001.

SEGENREICH, S. C. D. O PDI como referente para avaliação de instituições de educação superior: lições de uma experiência. Ensaio: aval. pol. públ. educ., Rio de Janeiro, v. 13, n.47, p. 149-168, abr./jun. 2005. Disponível em http://www.scielo.br/pdf/ensaio/v13n47/v13n47a03.pdf

STAKE, R. The Art Of Case Study Research. Sage Publications, 2005.

TARDIEU, H; GUTHMAN, B. Le triangle stratégique: Stratégie, structure et technologie de l'information. Paris. Les Editions de l'Organisation, 19992.

TIDD, J.; BESSANT, J.; PAVITT, K. Managing innovation: integrating technological, market and organizational change. 3.ed. England: John Wiley \& Sons, 2005.

VENKATRAMAN, N. IT induced business reconfiguration. In: The corporation of the 1990s: information technology and organizational transformation. New York: Oxford University Press, 1991. p. 122-158.

VICENZI, T. K. O alinhamento entre a estratégia de negócio e a estratégia da tecnologia da informação: um estudo na Universidade Regional de Blumenau (FURB). Dissertação de Mestrado, 1998. 